\title{
Progesterone vaginal ring: Prevents pregnancy
}

Population Council

Follow this and additional works at: https://knowledgecommons.popcouncil.org/departments_sbsr-rh

Part of the Demography, Population, and Ecology Commons, Family, Life Course, and Society Commons, International Public Health Commons, Maternal and Child Health Commons, and the Women's Health Commons How does access to this work benefit you? Let us know!

\section{Recommended Citation}

"Progesterone vaginal ring: Prevents pregnancy," fact sheet. New York: Population Council, 2015. 


\section{PROGESTERONE VAGINAL RING PREVENTS PREGNANCY}

\section{Vaginal rings are a novel way of delivering contraceptives. The Progesterone Vaginal Ring (PVR) is a vaginal ring which contains progesterone and can prevent pregnancy.}

The PVR has clinically been proven to be a safe and effective method of contraception for lactating women. When used by lactating women it prevents pregnancy in a number of ways. It:

- Inhibits follicular growth and hence prevents ovulation.

- Reinforces the inhibitory effect of breastfeeding on ovulation.

- Extends postpartum amenorrhea.

- Thickens the cervical mucus, thus inhibiting sperm-from meeting the egg.

\section{THE EVIDENCE}

The effectiveness of the PVR in preventing pregnancy has been demonstrated in three key areas:

\section{PREVENTION OF OVULATION}

A complex system of communication from the hypothalamus to the pituitary to the ovaries governs ovulation. This communication system regulates the production of two hormonesthe Follicle-Stimulating Hormone (FSH) and the Luteinizing Hormone (LH)-that are key for informing the ovaries to produce and release an egg. In a menstrual cycle, the effect of $\mathrm{FSH}$ is to grow follicles to house an egg and for $\mathrm{LH}$ to initiate release of the egg into the Fallopian tube. LH also sends signals to produce progesterone and to prepare the endometrium for a possible pregnancy. Progesterone's role is to inhibit the development of a new follicle. If the egg is not fertilized, progesterone levels drop after 14 days and the endometrium breaks down and the next menstrual bleeding occurs.

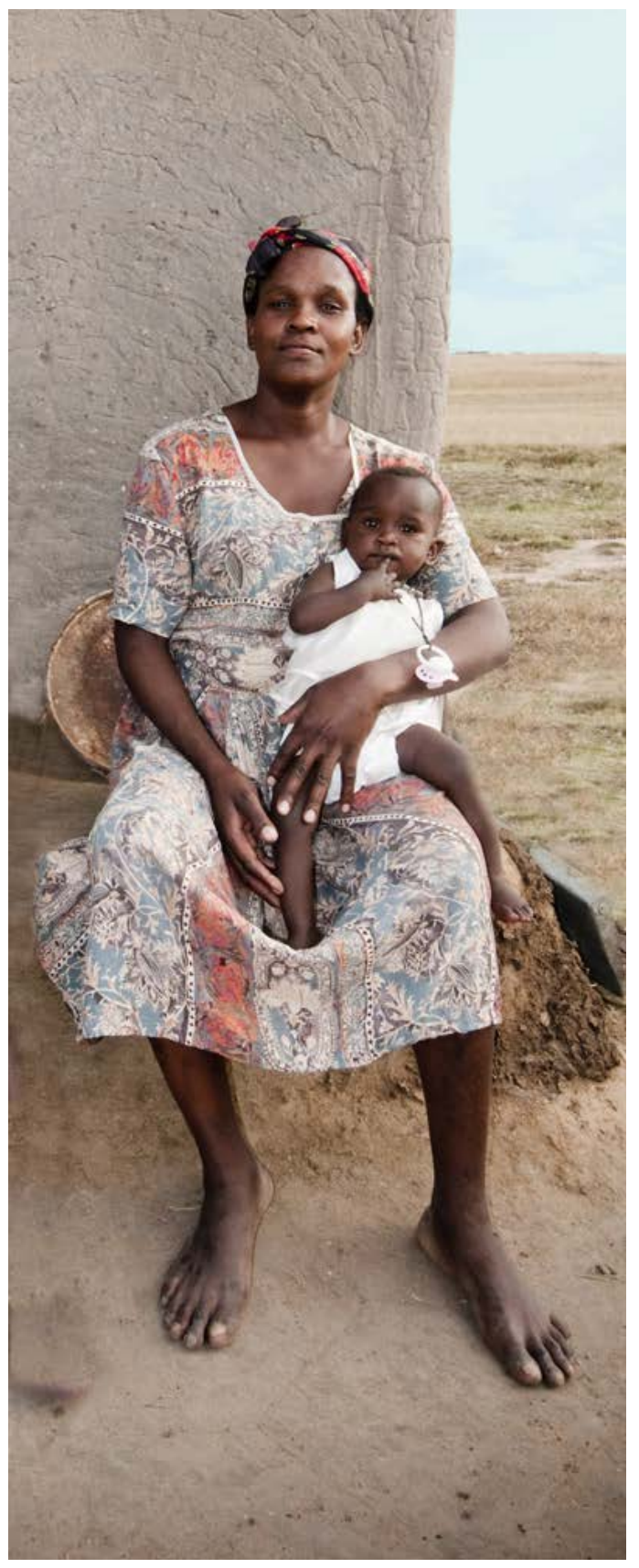




\section{THE PVR WORKS BY:}

- Delivering a small quantity of progesterone acting both on ovulation and cervical mucus. The progesterone in the ring is diffused into the vaginal walls and then into the blood stream.

- reinforcing the effect of the baby's suckling on the mother's production of the FollicleStimulating Hormone (FSH) and the Luteinizing Hormone (LH). The effect of suckling on the hypothalamus-pituitary ovarian response results in the suppression of FSH and LH. In turn, the reduced levels of FSH and LH causes a delay in ovulation.

- increasing the prolactin response to suckling. Prolactin is the hormone that stimulates and maintains the production of milk, and progesterone enhances prolactin production. Mothers are therefore able to nurse her baby for longer than otherwise possible, and longer breastfeeding durations extend the postpartum amenorrheic period.

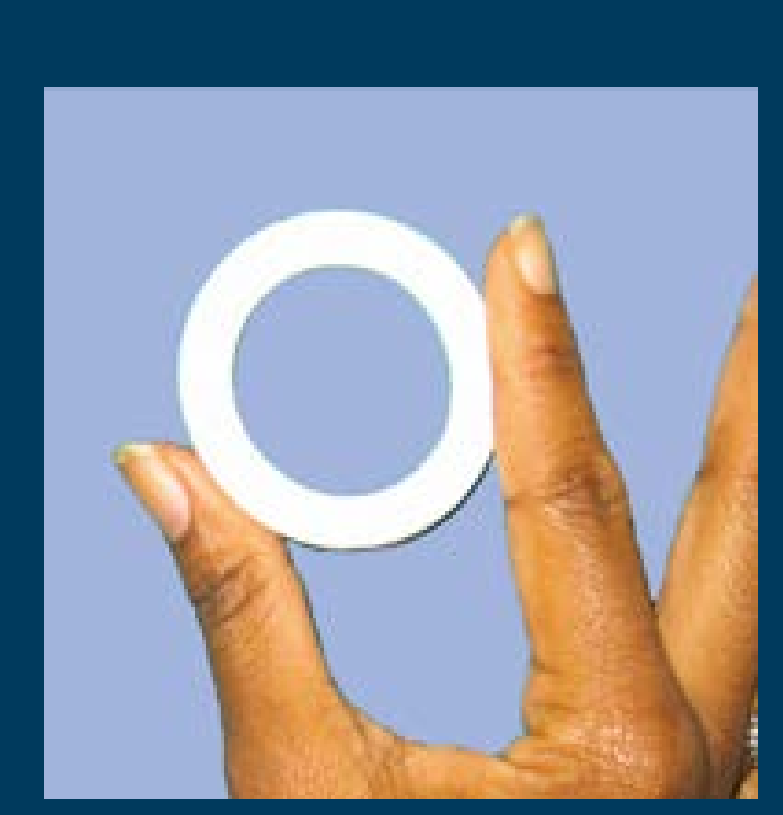

SOURCES: Diaz et al. 1991; McNeilly, Tay and Glasier 1994; Labbok 2008; Simpson-Herbert and Huffman 1981.)

\section{REINFORCEMENT OF THE EFFECT OF BREASTFEEDING ON OVULATION}

Breastfeeding too plays a role in delaying the resumption of normal ovarian cycles after delivery. The baby's suckling at its mother's breast suppresses the production of FSH and LH required for ovulation (McNeilly, Tay and Glasier, 1994; McNeilly, 1997). We know that suckling sets off a chain reaction of signals from the hypothalamus to the pituitary to the ovaries thereby regulating ovulation. As the baby nurses less as it grows the suckling response fades. As the suckling response reduces, FSH and LH resume their normal levels and signaling processes, sustainable follicles develop, and ovulation occurs.

\section{EXTENSION OF LACTATIONAL AMENORRHEA}

Lactational amenorrhea is the natural infertility that occurs immediately after childbirth. How long a woman is amenorrhic depends on how long and how frequently she breastfeeds. The duration of breastfeeding depends on a number of factors including a mother's ability to breastfeed, her interest in doing so, and the timing of introduction of weaning foods. Higher rates of amenorrhea have been observed among PVR users than IUD users in a comparative trial of the two methods; amenorrhea on average is five months longer (cited in Massai et al. 2000).

\section{EXPANDING CONTRACEPTIVE OPTIONS}

In 2015, the PVR has been added to the World Health Organization's (WHO) Essential Medicines List (EML) and Medical Eligibility Criteria (MEC) for Contraceptive Use guidance for providers.

\section{SUMMARY}

The PVR expands the range of contraceptives available to lactating women. It has been proven to be safe and effective. It has the potential to contribute to improving maternal and infant health.

\footnotetext{
References

Díaz, Soledad, P. Miranda, A. Brandeis, H. Cárdenas, and Horacio B. Croxatto. 1991. “Mechanism of action of progesterone as contraceptive for lactating women. In Frontiers in Human Reproduction Part II": Contraception and Sterilization. Eds. M. Seppala and L. Hamberger, Annals, New York AcadPart II": Contraception and Sterl
emy of Sciences, pp: 11-21.

Labbok, M. 2008. "Breastfeeding, fertility and family planning." In J. Sciarra (ed.). Fertility Regulation, Psychosomatic Problems, and Human Sexuality. The Global Library of Women's Medicine. DOI: 10.3843/GLOWM.10397

McNeilly, Alan S. 1997. "Lactation and fertility" Journal of Mammary Gland Biology and Neoplasia 2(3): 291-298.

McNeilly, Alan S., Clem C.K. Tay, and Anna Glasier. 1994. "Physiological mechanisms underlying lactational amenorrhea" Annals of the New York Academy of Sciences 709: 145-155.

Massai, Rebeca, Soledad Diaz, Ted Jacaanicz, and Horacio B. Croxatto. 2000. “Vaginal rings for contraception in lactating women" Steroids 65: 703-707.

Simpson-Herbert, Maylin and Sandra L. Huffman. 1981. "The contraceptive effect of breastfeeding"
} Studies in Family Planning 12(4):125-133.

CONTACT INFORMATION

For more information about the Council, please refer to our website at www.popcouncil.org 